\title{
Pervasive CSCW for Smart Spaces Communities
}

\author{
Christopher Lima, Diogo Gomes, Rui Aguiar \\ Universidade de Aveiro \\ IT - Instituto de Telecomunicações \\ Aveiro, Portugal \\ \{cviana, dgomes, ruilaa\}@av.it.pt
}

\begin{abstract}
Future pervasive environments will take into consideration not only individual users' interest, but also social relationships. In today's scenarios, the trend is to make use of collective intelligence, where the interpretation of context information can be harnessed as input for pervasive systems. Therefore, social CSCW applications represent new challenges and possibilities in terms of use of group context information for adaptability and personalization in pervasive computing. The objective of this paper is to present two enterprise scenarios that support collaboration and adaption capabilities through pervasive communities combined with social computing. Collaborative applications integrated with pervasive communities can increase the activity's quality of the end user in a wide variety of tasks.
\end{abstract}

Keywords- Communities; context-aware groups; pervasive computing; social network; enterprise 2.0.

\section{INTRODUCTION}

CSCW (Computer Supported Cooperative Work) has been the target of several studies since Engelbart's [1] paper in 1968, demonstrating how to support collaboration using shared computers screens communicating over a network. Since then, much effort has been dedicated to the design of collaborative applications that support individuals who are in a synchronous collaboration (e.g. video conference, shared screens), and individuals who interact in asynchronous way (e.g. wiki, email). These efforts generally aim to create virtual spaces to promote collaboration by providing mutual awareness, communication and coordination [8].

In 1988, Grudin [2] already raised problems in development and success of CSCW applications to a critical mass of users, in which large systems affect many people and benefits only a few users and not the entire collective. For example in enterprise scenarios, most of these problems are related to different roles that a person can have besides the individual and group differences [4]. The context awareness provides information about users and groups by exploiting their roles, beliefs and intentions. Context can be any relevant information available about location, users, services, devices and their relationships. Thus with the context information available from ubiquitous and pervasive environments it is possible to anticipate needs, personalize services and negotiate services anywhere and anytime.

An important aspect of pervasive environments is the integration of devices such as tablets and smartphones and intelligent watches with the environment that surrounds the user. The migration among these smart environments should be done as naturally as possible, seamlessly adapting the user application. In today's scenarios, pervasive systems lack the ability to deal with social group context besides the individual. Ackerman [3] highlighted that human computer interaction (HCI) and CSCW systems need to have at their core an understanding of how people really work and live in groups, organizations, and other forms of collective life. The social interaction is an authentic activity and by itself pervasive, taking place in people's everyday professional and personal lives. Thus, social networks provide opportunity to access detailed contextual information that is hard to achieve in other ways. With the advent of Web 2.0, various digital social communities have emerged in the present scenario like Facebook, LinkedIn and Twitter.

Thus, many companies following the Web 2.0 trend started to adopt the same platform but focusing in the enterprise field. The enterprise 2.0 refers to the use and spreading of the social software sharing philosophy among employees of the same enterprise, as well as beyond enterprise boundaries. The collective intelligence (CI) takes an important role with influences of Web 2.0 tools adoption inside company and organizations.

In order to illustrate the potential of CSCW, contextaware group and social paradigms integrated, we will present two enterprise scenarios, which envisage collaboration in pervasive communities. The scenarios aims to demonstrate that superior CSCW applications could be achieved by using social context-aware merged with social computing for the benefit of participants in collaborative activities.

The remaining of this paper is organized as follows: Section II presents the related work regarding the integration of $\mathrm{CSCW}$ with pervasive environments, context-aware group and social computing. Section III introduces the applicability of the concepts in two enterprise scenarios to address new social CSCW applications. Section IV identifies some keys challenges for future social CSCW applications. Finally, Section V provides a conclusion and possible directions for future work.

\section{BACKGROUND AND RELATED WORK}

Several approaches were implemented to enhance collaborative applications along the years. We present in this section the three key paradigms to improve CSCW activities: pervasive computing, context-aware group and social computing. 


\section{A. Pervasive Communities}

Pervasive environments have achieved a mature level, thanks to technology advances, mainly in sensors and mobile devices. The increase of portable devices such as smartphone and tablets is being exploited in ambient intelligence (AmI) to create rich applications involving adaptability of smart environments without explicit user intervention, taking environmental context into account. AmI can be used in applications such as healthcare, home care, transportation and environmental monitoring. Environments such as smart spaces are aware of context, where location/proximity (e.g. home, office), activities (e.g. walking, driving) and environment features (e.g. hot, cold) enabling users to access computational resources to perform their activities.

Smart spaces play an important role in the area of pervasive systems, providing an environment where users can interact electronically with other users and devices in the ambient. This is achieved by making the environment able to adapt itself to the user needs and by providing customized interfaces to the services available at each moment. Typically, these systems do not move with the user as shown in One.world [5], MavHome [6], or as in smart homes scenarios [7].

Especially in smart spaces, social awareness is important to create a group of users that cooperates effectively and successfully [15]. Considering this, smart spaces should enable users to create dynamic or static groups of interest to share common goals and tasks. According to [16], a community is spontaneously built and legitimizes various degrees of members based on its internal rules.

People who participate in such communities learn the accepted work practices, interact with each other and become more productive. Some studies regarding groups in pervasive environments are available in the literature. PICO (Pervasive Information Community Organization), [17] presented a framework with the objective to create pervasive communities that can collaborate proactively in areas such as telemedicine, military and crisis management. This aims to achieve a sequence of events that can lead to the creation of communities. The framework can detect unusual activity from mobile devices and individually recognizes the occurrence of an extraordinary event. [18] proposed a context ontology to an organizational architecture composed of society, community and members identifying four requirements to build cooperation systems and ubiquitous environments: context-aware, role-based interaction, organizational structure and dynamism.

More recent approaches attempt to tackle the problem of pervasive communities supporting also mobile users. POPEYE project approached spontaneous virtual communities that can be formed in a $\mathrm{P} 2 \mathrm{P}$ fashion for collaborative work [13]. However, the main project focus is in transport issues, lacking in services integration and social computing.

In [12] it is proposed a framework to form communities according to users' interests and participation. It is applied recommendation and personalization algorithms to perform self-organization based on online social sites. Nonetheless the work only encompasses the context originated from online social sites, not providing management for face-to-face communities and integration in several pervasive environments.

Recent projects about pervasiveness such as PERSIST [14] and MobiLife [10] include platforms for context management system, discovery mechanisms, event notification, personal preferences, and cooperation between the entities. Although most of them provide a rich platform to create applications, they miss to take advantage of those features for collaboration in groups.

\section{B. Context-aware Group for CSCW Applications}

[19] defines context-aware or context information as the paradigm of computing that allows applications to discover and take advantage of contextual information. Context may vary depending on application functionality, user goals and deployment environment. Schilit, et al. [20] were the first to discuss context-aware in mobile computing, defining it as: location, the collection of nearby people, hosts, accessible devices, and the changes to such things over time.

The group context involves all the knowledge relating to a group of individuals, including group composition, rules, roles, goals, strategies, coordination procedures. In [15], social context is defined as the information relevant to the characterization of a situation that influences the interactions of one user with one or more other users. Borges [21] refers to social context requirements as a set of norms, rules, obligations and understandings that influence an individual's action with respect to a group in a particular situation.

Regarding use of context information in collaboration, in [9] the authors address the advantage of context-aware information from a group perspective. The authors demonstrate the use of context-aware in an organization, where person-to-person communication barriers are reduced. The context information of organizations, users and applications is used to trigger automatic selection of a conference tool (voice or chat). The conference is determined based on the needs of the collaboration, presence and availability information of the participants and media capabilities of the devices of the participants.

MobiLife [10] project for example, addressed the use context-aware group management for mobile devices focusing in developing ubiquitous applications and services. Nevertheless, no emphasis is given to CSCW. UbiCollab [8] project on the other hand, tries to create solutions supporting natural collaboration in distributed groups for AmI. However, UbiCollab approach is more towards merging context, CSCW and mobility, missing in social sensing aspect.

In summary, the proposals involving context-aware groups for collaborative work still lack on environment integration, mobility and social capital where synergy could enhance collaborative experiences.

\section{Social computing in enterprise}

Social computing became a very relevant field in the current IT industry, mainly due to the emergence of Web 2.0. With Web 2.0, it is possible to enable provision of content, goods and services in areas of life and business by anybody and everybody [14].

This new paradigm originated the crowd computing term, which targets the human interaction to share tasks 
and ideas making use of tools like blogs, wikis and social network sites (SNS). Leverage communication and collaboration is one of key features of Web 2.0 tools. Popular enterprise 2.0 technologies utilized by organizations to support business performance management are wikis and social networks. Wikis enable users to post text, sound, video; and edit with little or no restrictions. Social enterprise networks sites permit techniques such as social bookmarking, tagging, expertise profiles, etc. The social computing tools when combined produce knowledge that has broad uses across the organization.

Online social networks such as LinkedIn, Facebook and Twitter have gained much popularity nowadays. This trend is in part by these SNS provide external APIs exposing some of their functionalities. These functionalities enable the development of applications by third parties, which led to differences in available services among existing social networks. These applications allow access to various types of information, such as profile, activities occurred, buddy list, etc. Such APIs being utilized nowadays are the OpenSocial (e.g. hi5, LinkedIn and Orkut) and Facebook with Facebook Platform.

More recently, social enterprise network sites such as Chatter, SocialCast, Cyn.In and others have attracted the attention of companies. Like traditional SNS, enterprise SNS can provide means to retrieve data available from teamwork and users of the company which can be used by developers.

Particularly Google plus has recently received much attention due to their metaphor for social community circles. The circles represent a group of users which the user creates/edits to differentiate friends in order to disseminate/receive content. Albeit SNS such as LinkedIn and Facebook do have some kind of group feature, most of the users still do not use this feature.

Even being a relative new area, social computing integration with other applications is rising due the social context in a few collaborative areas such as healthcare, eGov and CSCL (Computer Supported Collaborative Learning).

\section{FUTURE SCENARIOS}

The following scenarios exemplify the concepts expressed, in which group context-aware can support CSCW applications as they work on pervasive communities scenarios.

\section{A. Newspaper Scenario}

In a journalistic scenario there are different expertise profiles of employees, which often interact in different levels of tasks and hierarchy. Editors, reporters, photographers and freelancers can belong to a global pervasive community called the "Daily Times Press" that includes the whole editorial and all the subsequent sections.

The employees are also members of the internal newspaper SNS enabling them to share and follow professional content, available only for subscribed communities in the editorial. Each employee can be part of sub-communities, grouped by their work section in the newspaper (e.g. sports, finance) receiving only information relevant to their activities. These areas of interests reflects directly in the sub-communities, in which the interaction within the members is done with less privacy restriction and more information access level than the larger community of "Daily Times Press". This distinction among sub-communities enables content and context information to be exposed differently for each smaller community. For example, in a photographer's community who work for multiple sections of the newspaper, it is desirable that content related to photos is disseminated primarily to this group. With the formation of these communities it is possible for the members to automatically share their content (wiki comments, posts) and resources (printers, projectors)

Through the interaction among members and respective communities it is possible to acquire context information, interests and preferences of the community and each participant. All this information can be used by the community, which can predict and take decisions automatically. Based on the member's behavior it is possible to take into account all their professional agendas to auto-schedule meetings that suit everyone, present relevant information related to activities in mobile phones, invite members to join tasks based on profile skills.

Besides the newspaper static communities, it is important the formation of dynamic communities on the fly, especially to perform a common task in a short period of time. This type of situation is frequently in many companies, where you setup usually a smaller group of individual and ungroup them after the goals are reached. In a practical example, a dynamic community of reporters and photographers can be formed to cover a given journalistic event.

Typically in journalistic situations, the crews are often in the street, without opportunities to conduct face-to-face meetings. Through smart devices (e.g. digital cameras, tablets) it is possible to make available pictures, videos, interviews and other contents about the event in real time to the community members such as editors and others reporters. This fast availability of content allows editors to start working on the news story very quickly for publication. Pictures taken on location can be sent with geotag's to the newspaper cloud. Audio and video content such as interviews can also be treated in the same way; sent and stored in the newspaper cloud services with geotags and timestamps.

The choice of a conferencing tool is important in cases where mobile collaboration is needed between the reporters, whom are out covering up facts and editors whom are preparing the newspaper section in the office building. The prediction of collaboration tools like chat, audio and video in these situations is very important in terms of location. In addition, the conferences can be pre-scheduled or postpone taking into account the time and priority from reporters and editors agendas.

Service schedule, media storage and content management can be done in the editorial cloud service, creating a rich history of content. In addition, each community can comment, publish articles, upload photos and recorded material generating a material for subsequent queries. This content also enables to find professionals through their skills and professional 
experiences for a given task. Information available from outside the editorial cloud such as social networking (e.g. LinkedIn) and discussions, since it can contain professional context, may also be integrated as part of the material to enrich the newspaper searches.

The communities also can exchange information and content through inter editorial communities, respecting the privacy level of individuals and communities. Today, with the relatively easy availability of mobile devices it is possible to keep the employees aware of real-time activities, by subscribing services of the newspaper's cloud. Treating each community differently is important for the group and the members as well, where preferences of participants can personalize community behavior.

\section{B. Health Scenario}

In the local hospital the doctors, nurses and specialists belong to the same major community, called "St. Mary's Hospital" community. Each member of the hospital staff is grouped by specialty and/or specialized centers forming sub-communities.

The doctors are equipped with a smartphone/tablet that is carried all time on the hospital. All the notifications related to current patients are received in the doctors' device depending on the community involved in care. The notifications can be information including laboratory analyses, electronic medical records (EMR), emergencies and availability of surgery rooms/devices.

Each community of medical professionals provides information such as presence, availability and indoor location for the St. Mary's Hospital community and the ER community.

Display screens are positioned in some hospital places to present information to the community members: e.g. to find other members in the building and what activity are they conducting. Personalized screens will show information based on the member's community. When a member stays in front of the display, the sensor detects his presence and knows the communities which he/her are inserted. All the community information exchanged between the devices and St. Mary's Hospital community is granted through security and trusted mechanisms.

Typically, EMR systems store and retrieve history of the patient, clinical analysis, x-rays, dates of appointments, etc. Each patient carries a radio frequency identification (RFID) in the fist, which can be read by the mobile device, informing the patient's situation. Any new information from the patient sensors or clinical analysis is sent to the community in charge of the patient since his hospital check-in.

A central system orchestrates the medical ambient of the hospital. The environment, particularly surgery rooms and medical appliances (e.g. magnetic resonance imaging), is equipped with sensors that send information directly for the St. Mary's Hospital community. This capability allows for the allocation and schedule of resources as soon as available.

Daily procedures at the hospital demand temporary communities, which are to be formed dynamically. These dynamic communities can be formed for a surgery procedure, diagnosis meeting and videoconferences, aggregating professionals from different skills. In surgeries for example, communities can be formed quickly to attend emergencies, considering the availability and presence of the doctors.

Videoconferences between doctors are set up using 3D cameras that allow for the use of augmented reality in the explanation of medical facts and techniques for diseases and surgery. The context from participants can be used to present information on the screen (e.g. name of colleagues by face recognition, specialty). In the laboratory, medical residents can digitally tag equipment with information such as results/tips to help the next resident operate the device. These messages can be represented by air tags [22], which users can visualize via tablet or smartphones with equipped camera. The St. Mary's Hospital community enables the prioritize resources (e.g. medical appliances) and services, for the sake of emergencies. In addition, technical problems can be addresses quickly, by alerting automatically the technical community for the repair.

\section{Features and Challenges}

The following tables highlight the key features extracted from each scenario. Further, section IV discussed in more details the research challenges shown in both tables. Table I represents the newspaper scenario while Table II the health scenario.

TABLE I.

\begin{tabular}{|c|c|c|}
\hline \multicolumn{3}{|c|}{ Newspaper Scenario } \\
\hline Features & Supported by & Challenges \\
\hline $\begin{array}{l}\text { Community } \\
\text { and sub- } \\
\text { communities } \\
\text { formation }\end{array}$ & $\begin{array}{l}\text { Static and dynamic groups } \\
\text { based on social interaction. } \\
\text { Use of group context- } \\
\text { aware }\end{array}$ & $\begin{array}{l}\text { Recomendation } \\
\text { algorithms and group } \\
\text { context-aware sensing, } \\
\text { decision-making }\end{array}$ \\
\hline $\begin{array}{l}\text { Automatic } \\
\text { dissemination } \\
\text { of } \\
\text { information } \\
\text { and resources } \\
\text { in } \\
\text { communities } \\
\end{array}$ & $\begin{array}{l}\text { Broadcast information in } \\
\text { group. Resource sharing } \\
\text { among communities based } \\
\text { on context-aware and } \\
\text { preferences }\end{array}$ & $\begin{array}{l}\text { Group context } \\
\text { information } \\
\text { management in AmI. } \\
\text { Identification of } \\
\text { relevant individual. } \\
\text { Decision-making and } \\
\text { pro-activity behaviour }\end{array}$ \\
\hline $\begin{array}{l}\text { Community } \\
\text { behaviour }\end{array}$ & $\begin{array}{l}\text { Group preferences, group } \\
\text { prediciton and } \\
\text { group decision-making }\end{array}$ & $\begin{array}{l}\text { Group learning } \\
\text { algorithms }\end{array}$ \\
\hline $\begin{array}{l}\text { Media } \\
\text { content/histo- } \\
\text { ry }\end{array}$ & $\begin{array}{l}\text { Media content } \\
\text { management for } \\
\text { communities, archive of } \\
\text { content }\end{array}$ & $\begin{array}{l}\text { Content management } \\
\text { based on group } \\
\text { context-aware. Storage } \\
\text { of massive content in } \\
\text { cloud for AmI }\end{array}$ \\
\hline $\begin{array}{l}\text { Adaptation } \\
\text { and prediction } \\
\text { for } \\
\text { collaborative } \\
\text { tools }\end{array}$ & $\begin{array}{l}\text { Context sensors, location } \\
\text { awareness, personalization } \\
\text { of the tools by dynamic } \\
\text { context. }\end{array}$ & $\begin{array}{l}\text { Reasoning and pro- } \\
\text { activity behaviour for } \\
\text { groups }\end{array}$ \\
\hline $\begin{array}{l}\text { Communities } \\
\text { participation }\end{array}$ & $\begin{array}{l}\text { Suggestion, follows to } \\
\text { individuals, } \\
\text { communication among } \\
\text { groups and social } \\
\text { integration }\end{array}$ & $\begin{array}{l}\text { Recomendation } \\
\text { systems based on } \\
\text { group context-aware. } \\
\text { Integration with SNS, } \\
\text { pro-activity behaviour }\end{array}$ \\
\hline $\begin{array}{l}\text { Community } \\
\text { management }\end{array}$ & $\begin{array}{l}\text { Intra/inter community } \\
\text { communication, } \\
\text { merging/split of } \\
\text { communities capability. }\end{array}$ & $\begin{array}{l}\text { Intelligent mechanisms } \\
\text { for communities } \\
\text { relationships }\end{array}$ \\
\hline
\end{tabular}

TABLE II.

\begin{tabular}{|c|c|c|}
\hline \multicolumn{3}{|c|}{ Health Scenario } \\
\hline Feature & Supported by & Challenges \\
\hline $\begin{array}{l}\text { Community } \\
\text { and sub- } \\
\text { communities } \\
\text { formation }\end{array}$ & $\begin{array}{l}\text { Static and dynamic groups } \\
\text { based on social interaction. } \\
\text { Use of group context- } \\
\text { aware formation }\end{array}$ & $\begin{array}{l}\text { Recomendation } \\
\text { algorithms, learning } \\
\text { algorithms and group } \\
\text { context-aware analyses }\end{array}$ \\
\hline
\end{tabular}




\begin{tabular}{|l|l|l|}
\hline \multicolumn{3}{|c|}{ Health Scenario } \\
\hline \multicolumn{1}{|c|}{ Feature } & \multicolumn{1}{|c|}{ Supported by } & \multicolumn{1}{c|}{ Challenges } \\
\hline $\begin{array}{l}\text { Notifications } \\
\text { received by } \\
\text { medical staff }\end{array}$ & $\begin{array}{l}\text { Intra/inter community } \\
\text { communication. Context- } \\
\text { aware groups and } \\
\text { situational context }\end{array}$ & $\begin{array}{l}\text { Find relevant people } \\
\text { and communities } \\
\text { based on real-time } \\
\text { context. Pro-activity } \\
\text { behaviour }\end{array}$ \\
\hline $\begin{array}{l}\text { Presence and } \\
\text { availabilty }\end{array}$ & $\begin{array}{l}\text { Location-aware and } \\
\text { situational context }\end{array}$ & $\begin{array}{l}\text { Discovery people by } \\
\text { precision indoor } \\
\text { location. Real-time } \\
\text { state of the individual }\end{array}$ \\
\hline $\begin{array}{l}\text { Real-time } \\
\text { patient } \\
\text { information }\end{array}$ & $\begin{array}{l}\text { Group communication, } \\
\text { dissemination, information } \\
\text { management }\end{array}$ & $\begin{array}{l}\text { Group hierarchy } \\
\text { management in AmI, } \\
\text { decision-making } \\
\text { algorithms and pro- } \\
\text { activity }\end{array}$ \\
\hline $\begin{array}{l}\text { Medical } \\
\text { ambient } \\
\text { orchestration }\end{array}$ & $\begin{array}{l}\text { Management of devices, } \\
\text { services orchestration in } \\
\text { Ami }\end{array}$ & $\begin{array}{l}\text { Orchestration of } \\
\text { people and devices for } \\
\text { pervasive } \\
\text { communitites }\end{array}$ \\
\hline $\begin{array}{l}\text { Temporary } \\
\text { communities } \\
\text { for activities }\end{array}$ & $\begin{array}{l}\text { Creation of dynamic } \\
\text { groups on the fly, context- } \\
\text { aware }\end{array}$ & $\begin{array}{l}\text { Auto-discovery people } \\
\text { based on context. } \\
\text { Context management } \\
\text { lifecycle. Reasoning } \\
\text { and pro-activity }\end{array}$ \\
\hline $\begin{array}{l}\text { Videoconfere } \\
\text { nces with } \\
\text { social } \\
\text { augmented } \\
\text { reality }\end{array}$ & $\begin{array}{l}\text { 3D camera sensors, 3D } \\
\text { microphone, face and } \\
\text { audio recognition }\end{array}$ & $\begin{array}{l}\text { Individual and group } \\
\text { context-aware } \\
\text { filtering. Reasoning, } \\
\text { pro-activity for } \\
\text { groupware }\end{array}$ \\
\hline $\begin{array}{l}\text { Augmented } \\
\text { reality } \\
\text { message tag }\end{array}$ & $\begin{array}{l}\text { Mobile device, user } \\
\text { preferences. Present } \\
\text { context related to a } \\
\text { community }\end{array}$ & $\begin{array}{l}\text { Group context-aware, } \\
\text { reasoning, social } \\
\text { integration }\end{array}$ \\
\hline
\end{tabular}

\section{RESEARCH CHALLENGES}

Presently, many challenges need to be investigated for treating not only individual context information, but collective interests and preferences. In CSCW the concern lies primarily in small groups for collaborative activities. Below, follows the key requirements identified presented in tables I and II for context-aware CSCW applications:

\section{A. Context-Aware Groups and Social Integration}

The context information can be acquired through facts and situations, both in individual and group activities. The context information can come from social sensors and pervasive sensor [11]. The social sensors refer to activities in the digital world such as post or updates on a SNS, while the pervasive sensors are due from information of current situation or location in the physical world (usually through mobile devices). While pervasive sensors have some solutions in the literature is still a lack of social sensors solutions. Another open issue in both cases is the separation of the particular context of the professional.

It is essential to define mechanisms to interpret relevant context-awareness information to CSCW applications, including social computing information in order to provide new tools for pervasive environments. For example, enabling collaborative applications to take advantage of available information in traditional SNS (e.g. Facebook, LinkedIn) and enterprise SNS (e.g. Chatter, SocialCast), and use them as generators of inferences and suggestions.

Future directions, show that is possible to make available not only information from one SNS but from many sources. There are recent initiatives, such as Diso, OneSocialWeb and Diaspora, trying to create open standards for communication among SNS, embracing the
Decentralized Social Networking Systems (DSNS) ideology.

To manage and gather context, it is usual in the literature a context management. A context history repository (CHR) becomes necessary to store situation and interaction of the individual(s) to establish trends and predict actions. Data mining algorithms are responsible to identify context information and enable efficient context estimation. However, research in group context is it a new field and remains many open challenges.

\section{B. Group Learning and Reasoning}

Through group context management it is possible to enhance learning and reasoning mechanism for pervasive systems. Learning techniques allow quick response to changes that can occur in different places and in a variety of tasks. Thus, different learning algorithms can be applied to the information, including for instance rule based learning, neural network and Bayesian networks. As known in this field, each algorithm has its own advantages and disadvantages, therefore it is important to determine which techniques and algorithms best suits different situations in a collective perspective.

The reasoning mechanism is in charge to enhance the context management, filtering relevant content for a community and identifying people/information. Moreover, this enables the decision-maker to take into account the quality of context, confidence and what was learned for an appropriate decision. Thus, reasoning methods need to be investigated to focus both individual and group context.

Additionally, another important aspect for learning and reasoning is aggregate collaborative media content. Content media from chat conversations, comments in blogs/wikis as well as audio/video conference are sources of rich context information that can be extracted from the community behavior for predictions. For example, tags in subjects and posts in forums/wiki can reveal more about interests and preferences of the group.

Present mobile devices still do not have large computational resources and storage, at least enough to deal with very large amounts of information. The processing, management and availability of content can be implemented outside, that is, as services available in the cloud.

Another concern is with respect to group hierarchy management. Reasoning mechanisms are important when groups are splitted in small subgroups or when merged into a new group. In both cases, a solution needs to address the collaborative group content. The context information must take into account as well, in which the CHR needs to be updated for the new group(s). Even if a group becomes inactive, the collaboration content could be interesting for future inferences.

\section{Group Recommendation and Pro-active Behavior}

Pervasive systems need to be strongly proactive in order to minimize users' interaction. The interaction with user, user-to-environment and user-to-group can be explored in depth for collaborative activities in pervasive environments

In collaborative tasks the establishment of sessions can be classified into explicit and implicit. In an explicit session the members and their roles are defined before the session begins, usually by a coordinator that chooses 
manually the contacts to invite. On another hand an implicit session creates a spontaneous session, created as the system detects coherence between the involved participants and their activities. Implicit sessions are a challenge to CSCW and only a few works try to address this paradigm.

The purpose of recommendation systems is to suggest items to improve users' collaboration activities. The $\mathrm{CSCW}$ tools can take benefits from recommendations for example on topic of interest, suggestion of members to collaborate and automatic "follows" of areas of interest and members. Proactivity is desirable as well as recommendation. Since the proactivity is more intrusive than recommendation to users, the challenges are tradeoffs between automation and suggestion. Examples include creation of collaborative sessions based on context-aware, auto-tag subjects and medias, auto-post minutes of conferences sessions, auto-dissemination of the discussed information to the enterprise SNS and dynamic sharing resources to group.

A social prediction system is also necessary to handle issues for cooperation. For instance, the prediction should be aware of who will be attending a conference and then reschedule (e.g. based on actual location of the user) or even pre-scheduling meetings (based on group calendar) in other time slot. Moreover, social prediction for communities' interaction may be taken into consideration.

\section{SUMMARY AND DIRECTIONS}

This paper attempts to demonstrate through future scenarios and a set of requirements the new challenges and possibilities for groupware in pervasive communities. The inclusion of mechanisms of group learning, reasoning, social prediction and pro-activity using collective context information can enhance the participation of members before, during and after the collaborative session. Based on the paradigms presented, the scenarios exemplify daily interaction both in virtual life and real life, in which social context can be explored by application and services, especially for collaboration. In addition, the separation from personal and business context implies the challenge to share resources and information with a community. Identity and privacy are other aspects that need to be addressed for groups in pervasive environments.

Many challenges remain for interpretation of existing context related to groups such as attributes of, and associations among groups (to create, merge and subdivide communities). Context-aware CSCW applications merged with social networks can bring great benefits for AmI participants' usability. The social computing can be used to infer personalization for collaborative experience and dissemination. Through the knowledge of the context of a given group it is possible to manage groups' interest and to personalize the applications. Furthermore, we believe that pervasive and social context are central point to the development of systems for the future collaborative applications.

\section{ACKNOWLEDGMENT}

The authors wish to thank colleagues of PERSIST and SOCIETIES projects, without whom this paper would not have been possible.

\section{REFERENCES}

[1] Engelbart, D.C., English, W.K.: A research center for augmenting human intellect. In: Proceedings AFIPS Fall Joint Computer Conference, USA, pp. 395-41, 1968

[2] Grudin, J. Why CSCW applications fail: problems in the design and evaluation of organization of organizational interfaces. Proceedings of the ACM conference on Computer-supported cooperative work. USA, pp. 85-93, 1988.

[3] Ackerman, M. The Intellectual Challenge of CSCW: The Gap Between Social Requirements and Technical Feasibility. HumanComputer Interaction Journal, v15, pp 179-203, 2000.

[4] Cooper, A. : The inmates are running the asylum. Macmilla, 1999.

[5] Grimm R, Davis J, Lemar E, MacBeth A, Swanson S, Anderson T, Bershad B, Borriello G, Gribble S, and Wetherall S. System support for pervasive applications, 22(4): pp.421-486, 2004.

[6] Youngblood M.G., Holder L.B., Cook D.J. Managing Adaptive Versatile Environments, 3rd IEEE International Conference on Pervasive Computing and Communications, pp. 351-360, 2005.

[7] Intille, S.S. Designing a home of the future. IEEE Pervasive Computing, vol.1, no. 2, pp. 76-82. 2002.

[8] Farshchian, B, Divitini M. Collaboration Support for Mobile Users in Ubiquitous Environments. Handbook of Ambient Intelligence and Smart Environments, pp.173-199, 2010.

[9] John, A., Klemm, R., Mani, A., and Seligmann, D.D. Hermes: A Platform for Context-Aware Enterprise Communication. In Proceedings of PerCom Workshops, pp. 62-69, 2006.

[10] Coutand O. et al.,"Context-aware group management in mobile environments," 14th IST Mobile \&Wireless Communications Summit 2005, Germany, 2005.

[11] Rosi, A.; Mamei, M.; Zambonelli, F.; Dobson, S.; Stevenson, G.; Juan Ye; , "Social sensors and pervasive services: Approaches and perspectives" Pervasive Computing and Communications Workshops, pp.525-530, 2011.

[12] Foell, Stefan; Boessling, Philippe; Linner, David; Radusch, Ilja; Steglich, Stephan; "Self-Organizing Pervasive Online Communities," Autonomous Decentralized Systems, 2007. Eighth International Symposium, pp.403-410, 2007.

[13] E.M. Meyer, D. Wichmann, H. Büsch, S. Boll,"Location-based mapping services to support collaboration in spatially distributed workgroups". 4th International Conference on Collaborative Computing: Networking, Applications and Worksharing, 2008.

[14] I.Roussaki, N. Kalatzis, K.Doolin, N.K.Taylor,G.Spadotto, N.Liampotis and H.Williams, "Self-Improving Personal Smart Spaces for Pervasive Service Provision", in Towards the Future Internet, Eds. G. Tselentis, A. Galis, A.Gavras, S. Krco, V. Lotz, E. Simperl, B. Stiller and T.Zahariadis, IOS Press, pp. 193-203, 2010.

[15] Wang Z., Zhou X., Yu Z., Wang H. And Ni H.. Quantitative Evaluation Of Group User Experience In Smart Spaces. Cybernetics and Systems, Volume 41 Issue 2, 2010

[16] Wenger E., Snyder W. Communities of practice: the organizational frontier. Harvard Business Review., pp. 139-145, 2000.

[17] Kumar M., et al., "PICO: A Middleware Framework for Pervasive Computing," IEEE Pervasive Computing, Vol.2, No.3, 2003

[18] Kim M., Jung Y, Lee J., and Kim M.. Context-Based Cooperation Architecture for Ubiquitous Environment. LNCS, Ubiquitous Computing Systems: Volume 4239, pp. 171-182, 2006.

[19] Chen, G., and Kotz, D. A survey of context-aware mobile computing research. Research, Dept. of Computer Science, Dartmouth College, 2000.

[20] Schilit B. N, Adams N. I. and Want R. Context-Aware Computing Applications. In Proceedings of the Workshop on Mobile Computing Systems and Applications, pp. 85-90. IEEE, 1994.

[21] Borges, M.R.S. and Pino, J.A. "Awareness Mechanisms for Coordination Activities in Asynchronous CSCW". Proceedings of the $9^{\text {th }}$ Workshop on Information Technologies and Systems , USA, pp.69-74, 1999.

[22] Sekai Camera: http://www.sekaicamera.com/ 